\title{
Childhood sexual abuse and psychosis: data from a cross-sectional national psychiatric survey in England
}

Paul Bebbington, Sarah Jonas, Elizabeth Kuipers, Michael King, Claudia Cooper, Traolach Brugha, Howard Meltzer, Sally McManus and Rachel Jenkins

\section{Background}

A number of studies in a range of samples attest a link between childhood sexual abuse and psychosis.

\section{Aims \\ To use data from a large representative general population sample (Adult Psychiatric Morbidity Survey 2007) to test hypotheses that childhood sexual abuse is linked to psychosis, and that the relationship is consistent with mediation by revictimisation experiences, heavy cannabis use, anxiety and depression.}

\section{Method}

The prevalence of psychosis was established operationally in a representative cross-sectional survey of the adult household population of England $(n=7353)$. Using computer-assisted self-interview, a history of various forms of sexual abuse was established, along with the date of first abuse.

\section{Results}

Sexual abuse before the age of 16 was strongly associated with psychosis, particularly if it involved non-consensual sexual intercourse (odds ratio $(\mathrm{OR})=10.14$, 95\% Cl 4.8-21.3, population attributable risk fraction 14\%). There was evidence of partial mediation by anxiety and depression, but not by heavy cannabis use nor revictimisation in adulthood.

\section{Conclusions}

The association between childhood sexual abuse and psychosis was large, and may be causal. These results have important implications for the nature and aetiology of psychosis, for its treatment and for primary prevention.

\section{Declaration of interest}

None.
The increasingly well-established links between psychosis and distant trauma (often set in childhood) are at odds with purely neurobiological explanations. Many people have bad experiences as children, one of the most pernicious types being childhood sexual abuse. Understandably, the identification of sexual abuse depends on the definition, and on how the information is acquired. ${ }^{1}$ However, one UK survey found a prevalence of childhood sexual abuse of $11 \%$ in young adults, ${ }^{2}$ and estimates from elsewhere in the world have generally been in the same range. $^{3-5}$ The most recent Adult Psychiatric Morbidity Survey in England (APMS 2007) ${ }^{6}$ has detailed information about levels of childhood sexual abuse. Non-consensual sexual intercourse before the age of 16 was reported by $1.9 \%$ of the sample, unwanted sexual touching by $8.2 \%$, and uncomfortable sexual talk by $10.3 \% .^{1}$ Childhood sexual abuse exerts relatively nonspecific effects, being associated with many psychiatric manifestations. ${ }^{3,7-11}$ However, there is increasing evidence that the links between childhood sexual abuse and psychosis are especially strong, ${ }^{8,12-14}$ and they are of particular interest as they may illuminate the mechanisms by which psychotic symptoms emerge and are maintained. ${ }^{15,16}$ These mechanisms may involve particular psychological dispositions and the way these shape subsequent involvement with the material and social world. In this paper, we use the latest detailed data from APMS 2007. This enabled us to test the hypotheses in a large representative general population sample that childhood sexual abuse (i.e. before 16 years) is associated with psychosis, and that this association is proportionate to the severity of the abuse. We also hypothesised that the association would be mediated by anxiety, depression, heavy cannabis use and the experience of revictimisation.

\section{Method}

\section{Sample}

The data used in these analyses were acquired in APMS 2007 (the third national survey of psychiatric morbidity in British populations), ${ }^{6,17}$ based on a random sample of household residents aged 16 and over. This sample was designed to be representative of the adult population of England living in private households in terms of age, gender and region.

Fieldwork was carried out between October 2006 and December 2007. The survey adopted a multistage stratified probability sampling design. The sampling frame was the small user Postcode Address File. One adult aged 16 years or over was selected for interview in each household, using the Kish grid method. ${ }^{18}$ In total $9 \%$ of sampled addresses were reckoned to be ineligible because they contained no private households, leaving an eligible sample of 13171 addresses. Of those eligible to take part $57 \%$ agreed to an interview. Full interviews with 7353 people were carried out by experienced interviewers from the National Centre for Social Research. Selected participants were invited to take part in a second phase that included a clinical interview using the Schedules for Clinical Assessment in Neuropsychiatry (SCAN, version 2.1). ${ }^{19}$

\section{Procedure}

Ethical approval for APMS 2007 was obtained from one of the research ethics committees of the National Research Ethics Service appropriate for non-clinical populations. In line with standard British ethical guidance on non-clinical populations, 
only verbal permission was required once the project had been fully described to potential respondents in an advance letter. Respondents could ask for their data to be destroyed at any time. The phase-one interview involved computer-assisted personal interviewing, and collected detailed sociodemographic and clinical information. In addition, some information, including details of sexual abuse, was collected by passing the computer to the respondents and asking them to enter their own responses to questions (computer-assisted self-completion interview). The respondents were informed beforehand that the interviewers were unable to access the results of the self-completed parts of the interview.

\section{Measuring affect}

Non-psychotic psychiatric disorder was assessed during phase one with the Clinical Interview Schedule (revised) (CIS-R), ${ }^{20}$ which can be administered by non-clinically trained interviewers. In this paper, we have employed the facility of the CIS-R for providing separate overall scores for anxiety symptoms (range 0-8) and depressive symptoms (range 0-9).

\section{Assessment of cannabis use}

There is now considerable evidence for a causal link between cannabis use and psychosis. ${ }^{21}$ Sexual abuse is associated with an appreciable propensity to become dependent on street drugs. ${ }^{11}$ It is therefore plausible that cannabis consumption might mediate the association between sexual abuse and psychosis. The phaseone interview gathered detailed information about drug use. We opted to analyse levels of usage in testing for mediation, and identified participants who had used cannabis on more than 100 occasions as heavy users $(n=212$, weighted prevalence $2.9 \%)$

\section{Identifying psychosis}

In phase one, respondents were screened for possible psychosis. They were invited for a phase-two assessment if they met one of the following criteria:

(a) currently on antipsychotic medication;

(b) an in-patient stay for a mental or emotional problem in the past 3 months, or admission to a hospital or ward specialising in mental health problems at any time;

(c) a positive response to question $5 \mathrm{a}$ in the Psychosis Screening Questionnaire (PSQ). ${ }^{22}$ This covers auditory hallucinations;

(d) a self-reported diagnosis of psychotic disorder or symptoms suggestive of it.

Of the 7353 respondents who completed a phase-one interview, $313(4.3 \%)$ met at least one of these criteria. Of these, 64 refused to be followed up, leaving 249. Fifty-nine refused, or could not be contacted, leaving 190 (76\% of those approached) who provided a phase-two interview.

A definitive assessment of psychosis was based on SCAN, ${ }^{19}$ a semi-structured interview that provides ICD- $10^{23}$ diagnoses of psychotic disorder. Because SCAN requires interviewer judgement for the final identification of symptoms, the interviews were conducted by clinical interviewers. The presence of non-organic psychosis in the year before interview was established by applying ICD-10 diagnostic algorithms (CATEGO-V) ${ }^{19}$ to the SCANgenerated symptom ratings. Of the 190 screen positive participants who were assessed with SCAN, 23 had definite psychosis. However, in the analyses presented here, we used a measure of 'probable psychosis'. This category included the 23 SCAN positive individuals, together with a further 20 participants from the 123 who were not interviewed with SCAN. The latter were chosen because they met at least two of the phase-one psychosis screening criteria listed earlier. ${ }^{24}$ Thus our category of probable psychosis comprised 43 participants. Of these, 38 provided full information on sexual abuse.

\section{History of sexual abuse}

The 2007 survey included detailed enquiry about sexual abuse in the self-completion part of the first-phase interview. Respondents were asked about different levels of sexual abuse.

(a) Has anyone talked to you in a sexual way that made you feel uncomfortable?

(b) Has anyone touched you, or got you to touch them, in a sexual way without your consent?

(c) Has anyone had sexual intercourse with you without your consent?

Such events were dated precisely. Fourteen participants refused to answer, and other types of missing data brought the useable sample size down to 7298. In our analyses here we distinguish between childhood $(<16$ years) and adult sexual abuse (16+ years). Participants who had been abused in both periods were regarded as having experienced revictimisation.

\section{Weighting}

The survey data were weighted to take account of survey design and non-response, in order to render the results representative of the English household population aged 16 years and over. Weighting was necessarily complex, and is described in detail by McManus et al. ${ }^{6}$

\section{Analytic strategy}

We used the 'survey' commands in STATA 10.0 on Windows, which allow for the use of clustered data modified by probability weights, and provides robust estimates of variance. We first established the level of association between probable psychosis and the different types of childhood sexual abuse, providing values with and without adjustment for age, social class, educational level, grouped household income, ethnicity and whether the participant had been brought up by both biological parents. It should be noted that, of the sociodemographic factors listed, childhood sexual abuse was only associated with age (the oldest age groups reported less abuse) and with not being brought up by both biological parents at least until the age of $16 .{ }^{1}$

We then applied tests of mediation using generally accepted criteria. ${ }^{25}$ In this situation, mediation would require, first, that childhood sexual abuse was associated both with psychosis and with the putative mediators (revictimisation, anxiety score, depression score), and second, that the odds ratio for the relationship of sexual abuse to psychosis was reduced by adding the mediator to a model with psychosis as the dependent variable. If the relationship between psychosis and childhood sexual abuse was no longer significant after adding the mediator, it would be consistent with full mediation; if it was reduced but still significant, this would suggest partial mediation. We conducted logistic regressions, with probable psychosis as the dependent variable, entering as independent variables, first, measures of childhood sexual abuse, and then, the potential mediators. Again we conducted these analyses with and without adjustment for the sociodemographic information listed above.

Finally, we used Baron \& Kenny's criteria ${ }^{25}$ for moderation (an interaction between independent variable and moderator with a 
significant effect on the dependent variable) in order to analyse, separately, gender and an unhypothesised enhancement by revictimisation of the effect of childhood sexual abuse on psychosis. We repeated these analyses adjusting for demographic variables.

\section{Results}

We first present the relationship between probable psychosis and the different types of sexual abuse occurring both before and after the age of 16 (Table 1). However abuse is defined, the association with psychosis is strongly significant. We have established elsewhere that the abuse types form a plausible hierarchy, such that non-consensual sexual intercourse was generally the worst form, and uncomfortable sexual talk the least disturbing. ${ }^{1}$ No respondents reported experiencing sexual touching without one of the other forms as well. We therefore analysed the relative frequencies of psychosis in people reporting either of the two least distressing forms (sexual talk or touching), either of the two most distressing forms (sexual touching or non-consensual intercourse), and any of the three forms. These analyses are presented in Table 2 in terms both of odds ratios and of population attributable fractions (PAF). The association of uncomfortable sexual talk on its own with psychosis was not significant, and the PAF was less than 5\%. Non-consensual sexual intercourse had an odds ratio in excess of 10 , and a PAF of $14 \%$. The effects of creating a category of respondents who had experienced either sexual touching or non-consensual sexual intercourse ('contact abuse') reduced the odds ratio to less than 4 , but increased the PAF to $17 \%$. The use of an inclusive category, covering all forms of abuse, reduced the odds ratio further, but increased the PAF to $22 \%$. Adjustment for sociodemographic variables had the uniform effect of slightly increasing the odds ratios.

In order to test our hypothesis that the association of abuse with probable psychosis was proportional to the severity of abuse, we created a variable with four levels: no abuse; uncomfortable talk only; touching as the most severe form of abuse; and nonconsensual intercourse. By expanding the variable into its levels during logistic analysis, we were able to identify the odds ratios associated with each level of severity. The results are presented in Table 3. This confirms that by far the strongest effect is that

\begin{tabular}{|c|c|c|c|c|c|}
\hline \multirow[b]{2}{*}{ Survey question } & \multirow[b]{2}{*}{ All, \% $(n / N)$} & \multirow[b]{2}{*}{$\begin{array}{l}\text { Psychosis } \\
\%(n / N)\end{array}$} & \multirow[b]{2}{*}{$\begin{array}{l}\text { No psychosis } \\
\%(n / N)\end{array}$} & \multicolumn{2}{|c|}{ Statistics } \\
\hline & & & & $\chi^{2}$ (d.f.) & $P$ \\
\hline $\begin{array}{l}\text { Before } 16 \text { someone talked to you in a sexual way that made } \\
\text { you feel uncomfortable }\end{array}$ & $10.3(762 / 7292)$ & $29.0(13 / 38)$ & $10.2(749 / 7254)$ & 18.9 (1) & $<0.0001$ \\
\hline $\begin{array}{l}\text { Before } 16 \text { someone touched, or got you to touch them, } \\
\text { in a sexual way without your consent }\end{array}$ & $8.2(642 / 7299)$ & $25.8(12 / 38)$ & $8.2(630 / 7261)$ & 20.5 (1) & $<0.0001$ \\
\hline $\begin{array}{l}\text { Before } 16 \text { someone had sexual intercourse with you without } \\
\text { your consent }\end{array}$ & $1.9(144 / 7298)$ & $16.1(8 / 38)$ & $1.8(136 / 7260)$ & $63.5(1)$ & $<0.0001$ \\
\hline $\begin{array}{l}\text { After the age of } 16 \text { someone talked to you in a sexual way } \\
\text { that made you feel uncomfortable }\end{array}$ & $12.2(927 / 7300)$ & $32.3(14 / 38)$ & $12.1(913 / 7262)$ & $20.1(1)$ & $<0.0001$ \\
\hline $\begin{array}{l}\text { After the age of } 16 \text { someone touched, or got you to touch } \\
\text { them, in a sexual way without your consent }\end{array}$ & $5.0(397 / 7307)$ & $22.6(10 / 38)$ & $4.9(387 / 7269)$ & $32.4(1)$ & $<0.0001$ \\
\hline $\begin{array}{l}\text { After the age of } 16 \text { someone had sexual intercourse with you } \\
\text { without your consent }\end{array}$ & $2.6(215 / 7307)$ & $16.1(7 / 38)$ & $2.6(208 / 7269)$ & $32.0(1)$ & $<0.0001$ \\
\hline
\end{tabular}

\section{Table 2 Logistic regression of relationship between childhood sexual abuse and psychosis}

\begin{tabular}{|c|c|c|c|}
\hline & $\begin{array}{l}\text { Odds ratio } \\
(95 \% \mathrm{Cl})\end{array}$ & $\begin{array}{l}\text { Adjusted odds ratio } \\
\qquad(95 \% \mathrm{Cl})^{\mathrm{a}}\end{array}$ & $\begin{array}{l}\text { Population attributable } \\
\text { fraction }\end{array}$ \\
\hline (a) Uncomfortable sexual talk ${ }^{\mathrm{b}}$ & $1.03(0.23-4.8)$ & $0.88(0.1-6.7)$ & 0.046 \\
\hline (b) Sexual touching ${ }^{\mathrm{b}}$ & No cases & & N/A \\
\hline (c) Non-consensual sexual intercourse ${ }^{\text {b }}$ & $10.14(4.8-21.3)$ & $12.05(4.0-36.3)$ & 0.14 \\
\hline Uncomfortable talk or sexual touching (a or b above) & $2.77(1.4-5.3)$ & $3.21(1.3-7.7)$ & 0.18 \\
\hline Contact sexual abuse (b or c above) & $3.49(1.8-6.8)$ & $4.36(1.8-10.5)$ & 0.17 \\
\hline Any sexual abuse (a or b or c above) & $2.74(1.4-5.25)$ & $3.17(1.3-7.6)$ & 0.22 \\
\hline
\end{tabular}

Table 3 Logistic regression showing association of psychosis with different levels of childhood sexual abuse

\begin{tabular}{|c|c|c|c|}
\hline & Odds ratio $(95 \% \mathrm{Cl})$ & Adjusted odds ratio $(95 \% \mathrm{Cl})^{\mathrm{a}}$ & $P$ \\
\hline Uncomfortable sexual talk & $1.25(0.3-5.9)$ & $1.16(0.1-9.1)$ & 0.776 \\
\hline Sexual touching & $1.61(0.5-4.8)$ & $2.06(0.6-7.2)$ & 0.393 \\
\hline Non-consensual sexual intercourse & $10.66(5.0-22.9)$ & $14.95(5.2-43.1)$ & $<0.0001$ \\
\hline
\end{tabular}


of non-consensual sexual intercourse, and this was the only form that remained significant in this analysis, with an odds ratio of 10.7. When we repeated these analyses adjusted for sociodemographic factors, the odds ratios for childhood sexual abuse remained largely unchanged: there was an increase, albeit non-significant, in the odds ratio relating to non-consensual sexual intercourse. It is of interest that when sexual abuse and upbringing by both biological parents until the age of 16 were entered in the same analysis, there was no longer an association between upbringing type and psychosis.

We next examined the link between our supposed mediators and childhood sexual abuse. Separate analyses were carried out in relation first to contact abuse and then to non-consensual sexual intercourse.

The first requirement for mediation is that the putative mediator should be associated with childhood sexual abuse (see analytic strategy). Surprisingly this criterion was not fulfilled for heavy cannabis use. Nor was the latter associated with probable psychosis: no single person with psychosis reported heavy cannabis use, so we must conclude that the childhood sexual abuse/psychosis link cannot be mediated by it in this data-set.

Childhood sexual abuse was, however, associated with anxiety and depression scores and with revictimisation. Further preliminary analyses confirmed that depression and anxiety might both be candidates for mediating the childhood sexual abuse/ psychosis link. The depression score in those who had experienced contact abuse before 16 was more than twice that in people without abuse (1.4 (95\% CI 1.2-1.6) v. 0.6 (95\% CI 0.54-0.61), $P<0.0001)$. The results were similar for anxiety $(1.6$ (95\% CI $1.46-1.81)$ v. 0.8 (95\% CI $0.78-0.87), P<0.0001)$. In addition, the odds ratio linking psychosis to depression was 1.6 (95\% CI $1.4-1.9)$ and to anxiety 1.5 (95\% CI 1.4-1.8), both highly significant $(P<0.001)$.

Contact sexual abuse before 16 was very strongly associated with the same form of abuse after that age, with an odds ratio of 5.6 (95\% CI 4.5-7.0). Contact sexual abuse in adulthood was also strongly associated with psychosis $(\mathrm{OR}=5.0,95 \% \mathrm{CI}$ 2.5-10.2). This means that adult contact abuse might mediate the relationship between child contact abuse and psychosis.

However, the situation was different when abuse was defined in terms of non-consensual sexual intercourse. Non-consensual sexual intercourse in childhood strongly predicted adult nonconsensual sexual intercourse $(\mathrm{OR}=8.72,95 \%$ CI 5.8-13.1). However, the latter was, surprisingly, not associated with probable psychosis. The criteria for mediation are therefore only met by revictimisation defined in terms of contact abuse.

We then moved on to the final stage of mediation testing. We examined the effect of adding adult contact sexual abuse and anxiety and depression scores as independent variables to the logistic regression linking childhood contact abuse to probable psychosis (Table 4).

The effect of adult contact abuse was to reduce the odds ratio of childhood contact abuse from 3.5 to 2.3 (95\% CI 1.2-4.1). At the same time, the odds ratio for adult contact abuse was also reduced from 5.0 to 3.7 (95\% CI 1.9-7.0). This looks more like the partitioning of equivalent effects than the mediation of one effect by the other.

Adding anxiety score to the analysis of childhood contact abuse and probable psychosis reduced the effect of abuse considerably, such that it became barely significant. Incorporating the depression score in place of the anxiety score rendered the odds ratio for contact abuse non-significant. Incorporating the two affective variables together in a single analysis made little further difference to the link between contact abuse and psychosis.
We next analysed the impact of our affective measures on the link between non-consensual sexual intercourse in childhood and probable psychosis (Table 4). Anxiety and depression each considerably reduced the odds ratio (from 10 to 5.8 and to 4.1 respectively), although not to non-significant levels. Once more, analysing the three independent variables together made little difference to the pattern of results.

In these analyses, anxiety and depression individually met criteria for the partial mediation of the effects of non-consensual childhood sexual intercourse on psychosis. However, with both contact abuse and non-consensual sexual intercourse, the introduction of depression rendered the effect of anxiety nonsignificant. These results therefore raise the possibility that depressed affect might be more central to this process than anxiety.

Controlling for sociodemographic variables increased the odds ratios linking contact abuse with psychosis, but had little impact on the affective variables, and left the implication of mediation intact.

Finally, we examined whether revictimisation increases the likelihood that childhood sexual abuse is followed by probable psychosis. Note that this analysis is not about mediation, but about the magnification of the effect of childhood sexual abuse. Where contact abuse in childhood was followed by similar abuse in adulthood, the odds ratio increased from 3.49 (95\% CI 1.86.8 ) to 10.78 ( $95 \%$ CI 5.1-22.9). The equivalent change for repetition of non-consensual sexual intercourse was from 10.14 (95\% CI $4.8-21.3)$ to 17.65 (95\% CI 6.1-50.7). Statistically, such magnification is a form of moderation, even though the moderating variable post dates the moderated variable. This in turn implies that the magnification effect operates on some undefined mediator linking childhood sexual abuse with psychosis. In the case of contact abuse, it was possible to demonstrate formally that such moderation occurred, as the interaction term linking child and adult contact abuse was a

Table 4 The effects of adjusting for current anxiety and depression scores on the link between sexual abuse before the age of 16 and psychosis

\begin{tabular}{|c|c|c|}
\hline & $\begin{array}{l}\text { Odds ratio } \\
(95 \% \mathrm{Cl})\end{array}$ & $\begin{array}{l}\text { Adjusted odds } \\
\text { ratio }(95 \% \mathrm{Cl})^{\text {a }}\end{array}$ \\
\hline Contact abuse & $3.5(1.8-6.8)$ & $4.5(2.0-10.2)$ \\
\hline \multicolumn{3}{|l|}{ Combined analysis (1) } \\
\hline Contact abuse & $2.3(1.1-4.8)$ & $3.2(1.3-8.1)$ \\
\hline Anxiety score & $1.6(1.3-1.9)$ & $1.7(1.3-2.1)$ \\
\hline \multicolumn{3}{|l|}{ Combined analysis (2) } \\
\hline Contact abuse & $2.2(0.9-5.0)$ & $2.8(1.1-7.7)$ \\
\hline Depression score & $2.1(1.7-2.6)$ & $2.1(1.7-2.7)$ \\
\hline \multicolumn{3}{|l|}{ Combined analysis (3) } \\
\hline Contact abuse & $2.4(1.1-5.2)$ & $2.9(1.1-7.7)$ \\
\hline Anxiety score & $1.2(0.9-1.6)$ & $1.2(0.9-1.6)$ \\
\hline Depression score & $1.8(1.4-2.5)$ & $1.9(1.3-2.6)$ \\
\hline Non-consensual intercourse & $10.1(4.8-21.3)$ & $13.4(4.7-37.3)$ \\
\hline \multicolumn{3}{|l|}{ Combined analysis (1) } \\
\hline Non-consensual intercourse & $5.8(2.7-12.6)$ & $9.1(3.0-27.1)$ \\
\hline Anxiety score & $1.5(1.3-1.9)$ & $1.6(1.3-2.0)$ \\
\hline \multicolumn{3}{|l|}{ Combined analysis (2) } \\
\hline Non-consensual intercourse & $4.1(1.6-10.8)$ & $6.6(2.0-21.3)$ \\
\hline Depression score & $2.1(1.6-2.6)$ & $2.1(1.6-2.7)$ \\
\hline \multicolumn{3}{|l|}{ Combined analysis (3) } \\
\hline Non-consensual intercourse & $4.2(1.7-10.7)$ & $6.3(2.0-19.4)$ \\
\hline Anxiety score & $1.2(0.9-1.6)$ & $1.2(0.9-1.6)$ \\
\hline Depression score & $1.8(1.3-2.4)$ & $1.9(1.3-2.7)$ \\
\hline \multicolumn{3}{|c|}{$\begin{array}{l}\text { a. Adjusted for age, social class, educational level, household income, ethnicity and } \\
\text { whether the participant had been brought up by both biological parents until the } \\
\text { age of } 16 \text {. }\end{array}$} \\
\hline
\end{tabular}


highly significant predictor of psychosis. For non-consensual sexual intercourse, the interaction term was not significant. These results might mean that the magnification of effect of childhood sexual abuse by adult repetition is restricted to the less severe forms of abuse, possibly implying a ceiling effect when childhood abuse involves non-consensual sexual intercourse.

The potential moderation of these findings by gender is important. Males are less likely to be sexually abused in childhood than females ${ }^{1,9}$ and less frequently exhibit severe responses to trauma in general. ${ }^{26}$ In APMS 2007, there were, unexpectedly, fewer males with possible psychosis than females (13 v. 21). Moreover, among the males, there was only one individual with psychosis who had been subjected to contact abuse before 16 and none who had experienced non-consensual sexual intercourse. Of the 21 females with psychosis, 7 had had childhood contact abuse, whereas 5 had been forced to have sexual intercourse. Thus males showed no tendency for psychosis to be linked to sexual abuse, whereas the link remained highly significant in females. There is therefore prima facie evidence of moderation of the psychosis/sexual abuse relationship by gender. To test this formally, we conducted two sets of logistic regression analysis involving the relationship, respectively, of contact abuse and of non-consensual sexual intercourse before 16 with psychosis.

The effect of gender on the model was non-significant, and the odds ratios for the measures of sexual abuse remained highly significant (2.0 for contact sexual abuse, 9.3 for non-consensual sexual intercourse). However, when an interaction term linking sexual abuse and gender was entered, the association of sexual abuse and psychosis became non-significant, and the only significant term was now the abuse-gender interaction. This indicates strong support for moderation of the effect of sexual abuse by gender.

\section{Discussion}

\section{Summary of findings}

We found a strong association of psychosis with childhood sexual abuse, particularly when it involved sexual intercourse. This was maintained after adjustment for a range of sociodemographic variables. The association was not mediated by heavy cannabis use or by revictimisation experiences, although there did seem to be partial mediation by affect. Revictimisation had relatively little impact on the already strong association of childhood sexual intercourse with psychosis, but it magnified that of contact sexual abuse. In this sample the link between sexual abuse and psychosis was stronger in women.

\section{Methodological limitations}

The use of a random sample of the population removes nosocomial bias, but differential participation rates may distort the prevalence of psychosis and of sexual abuse, and the relationship between them. The most likely effect would be to reduce the prevalence of both elements, but it is not clear what effect this would have on their interrelationship, except in reducing statistical power. At 57\%, the response rate in APMS 2007 was less than in earlier surveys in the National Survey programme. ${ }^{17}$ We therefore conducted a sensitivity analysis to see if this level of refusal might affect the prevalence of sexual abuse. We dichotomised the sample according to the response rates seen in individual regions. We then used this new locational variable to compare the rates of endorsement of the computerassisted personal interviewing sexual abuse question. There was no significant association between location and prevalence. Nor was this the result of a lack of statistical power: the prevalence of abuse was very similar in the lower and higher responding areas (5.5\% and $4.9 \%$ respectively, $P=0.283$ ).

Just over half of those with psychosis had been diagnosed under the gold standard conditions of SCAN, whereas the rest were diagnosed by a score of over two on our screening procedures. Using the screening results in this way would have identified 19 of the 23 individuals identified by SCAN in any case. Thus the two methods produced closely overlapping outcomes, which we feel justifies our use of the category of probable psychosis in the current analyses.

For various reasons, accounts of sexual abuse may not be wholly accurate, although it is difficult to say how inaccurate. Such enquiry is particularly sensitive, although not everyone is equally subject to embarrassment or discomfiture. Sensitivity is likely to vary with time, and possibly with age. Some of the more minor forms of abuse might be forgotten, discounted or repressed with increasing age and changing perspective. Our category of uncomfortable sexual talk might be particularly subject to such distortion. Moreover, some specific forms of abuse would not have been identified by our questions, for instance intrusive exposure to pornography.

In contrast, non-consensual sexual intercourse is clearly abuse. It is thus more likely to be underreported than forgotten, and its acknowledgement will depend to an extent on the method of enquiry. The 2007 APMS involved strenuous efforts to maintain data quality, including stressing confidentiality and interviewing participants alone where feasible. In addition, there are particular advantages to computer-assisted self-completion interview, which generally elicits franker responses than face-to-face questioning. ${ }^{27}$ Thus, getting people to complete the questionnaire themselves on a laptop computer and making them aware that the interviewer would have no access to the answer was intended to encourage frankness. Even so, the way the questions were framed (i.e. in terms of consent) might lead to underestimation of abuse. Abused people might think they had in fact consented in some way, particularly if they had been groomed, or thought themselves to blame for their predicament.

Although the information about abuse and disorder was obtained cross-sectionally, at a single point in time, in the overwhelming majority of cases childhood sexual abuse ostensibly pre-dates what are, after all, current disorders. A causal inference is consequently easier to defend for childhood sexual abuse than for adult sexual abuse. It is, however, still subject to the caveat of systematic distortion of reportage, in whatever direction, by people with mental disorders. Counter to this, empirical research has generally found them to be reliable informants. Fergusson et $a^{28}$ assessed the stability of reports of childhood sexual abuse over a 3-year gap. They concluded that people who had not been abused did not falsely report otherwise. However, positive reports were unstable; false negatives may reach $50 \%$. Nevertheless, this did not materially affect estimates of the relative risk of associated psychiatric disorders. Set against this, there have been specific concerns about the reliability of reports of abuse in people affected by schizophrenia. However, Goodman et al ${ }^{29}$ showed that their accounts were consistent over time, and concluded that the information obtained is sufficiently reliable to allow research in this area. Similar results have been reported by Fisher and colleagues. ${ }^{30}$ Interestingly, they found that in $98 \%$ of individuals, the abuse preceded the psychosis.

Finally, confounding is a possibility, both for the basic analyses and for those involving mediation and moderation. We adjusted for sociodemographic variables, but these largely related to current, or a least adult, status. Thus educational level, income, and current social class relate to a date later than that of childhood sexual abuse, and would only have the power to confound if they 
served as proxies for lost opportunities in childhood. The impact of sexual abuse is likely to be greater than that of unspecified deprivation or poor parenting. However, although sexual abuse is likely to be strongly related to poor parenting, the reverse may not be true, so poor upbringing experiences may have separate effects. Upbringing arrangements provided the only proxy for poor parenting available to us in this study. However, there may of course be positive as well as negative effects of parental separation. Thus it was notable that not being brought up by both biological parents until 16 was no longer associated with psychosis when it was analysed together with abuse.

\section{Sexual abuse and psychosis}

The associations between reported childhood sexual abuse and probable psychosis were strong. In particular, the odds ratio linking psychosis with non-consensual sexual intercourse was over 10 , with a PAF of $14 \%$. It must be noted that the PAF is a statistical measure subject to the same reservations about causality as measures of association. Moreover, even with a large population sample, the confidence limits for the odds ratios are inevitably quite wide. Nevertheless, the values are at least suggestive of a major contribution of childhood sexual abuse to psychotic disorders.

Our findings were strongly moderated by gender, such that the link between sexual abuse and psychosis was far stronger in females. This is consistent with evidence from Myin-Germeys \& Krabbendam $^{31}$ that psychosis in females is a more socially reactive condition than in males. However, we must add a caveat. The distribution of psychosis by gender was different in the 2000 British Psychiatric Morbidity Survey, being identified in 30 males and 30 females. ${ }^{32}$ The relatively few cases of psychosis in males in the current study may have distorted our findings. Although in the 2000 survey information on sexual abuse was obtained in a different manner, with less precise dating, ${ }^{8}$ we were able to use it in an approximately equivalent analysis: this resulted in a non- significant abuse-gender interaction term, which did not replace the direct link between abuse and psychosis. Thus we must be cautious in placing weight on evidence of moderation in the 2007 survey.

Our results do support an emerging consensus linking childhood trauma with an increased risk of psychotic disorder or symptoms. This now comprises studies of increasing methodological sophistication, including some prospective studies. ${ }^{8,13,33-47}$ Our finding that most of the risk is conferred by the most severe form of childhood sexual abuse (i.e. nonconsensual sexual intercourse) is novel: less severe abuse, such as touching and inappropriate talk, was not on its own associated with psychosis, although it most certainly is with other disorders. ${ }^{11}$ However, there are a number of ways of quantifying severity that were not available to us such as the frequency of abuse and abuse by multiple perpetrators. Other studies of psychosis have reported more in the way of a dose-response relationship, variously measured. ${ }^{37,38}$

\section{Mediation of the abuse-psychosis relationship}

Sexual abuse in childhood is almost always an earlier event than the development of psychosis (the latter rarely emerges before 16 , the cut-off age used here to denote childhood sexual abuse). Any causal link between the two must therefore involve mediation, often operating over a considerable interval. From a theoretical perspective, it is relatively easy to conceive of experiential variables such as childhood sexual abuse leading directly to mental representations and dispositions that set a course for the subsequent development even of a complex mental disorder such as psychosis.

The design of the current study limits both our choice of possible mediators, and the weight we can place on our analyses. We were able to examine revictimisation, heavy stimulant drug use, anxiety and depression.

\section{Mediation by affect}

Our analyses are in line with mediation effects for the affective consequences of childhood sexual abuse. The relationship between childhood sexual abuse and probable psychosis was reduced by adjustment for affect, albeit remaining significant, except when depression was controlled in relation to contact abuse. Whereas depression and anxiety showed roughly equivalent effects, when they were entered into the analysis together, the effect of anxiety became non-significant, suggesting that depression had the greater relevance. Adjustment for potential sociodemographic confounders had no effect on the results. There is an assumption built into the use of current affective state (our measures were related to the week preceding interview), which is that the state measures can be used as an adequate indicator of a propensity to dysphoria. It is only the latter that could stand as a mediator. Factor analyses have suggested that abuse is associated with anxiety, and that anxiety is in turn associated with more severe symptoms, including the development and persistence of positive symptoms of psychosis. ${ }^{48-50}$ Such pathways are amenable to empirical testing, preferably by longitudinal studies, and to psychological intervention.

\section{Revictimisation and psychosis}

Somewhat surprisingly, for revictimisation, only the broader category represented by contact abuse after 16 met criteria for being a potential mediator. Non-consensual sexual intercourse after the age of 16 did not do so, as it was unrelated to psychosis. This discrepancy invites caution, as contact not involving sexual intercourse may be more subject to distortion of recall by psychiatric state. This result is in contrast with the findings of Read et al. ${ }^{51}$

Although revictimisation (however defined) did not meet criteria for mediation, the association between childhood sexual abuse and probable psychosis seemed to be augmented by revictimisation of either sort. Note that our definition of revictimisation was based only on the repetition of childhood abuse in adulthood. Thus it could not identify multiple abuse restricted either to childhood or to adulthood, and would therefore tend to underestimate the frequency and impact of multiple abuse over the life course.

The existing literature provides context for these findings: childhood sexual abuse is strongly associated with revictimisation, ${ }^{52}$ people who are abused as adults have higher rates of mental illness, especially schizophrenia, and psychiatric patients suffer significantly higher levels of adult abuse. ${ }^{53,54}$ The relationship between sexual abuse and psychosis thus appears to be associated alike with the severity and the repetition of abuse. However, revictimisation may merely be a marker for severity of abuse. It is also possible that this apparent relationship is the result of confounding by abuse that is secondary to adult mental illness.

\section{Heavy cannabis use}

In this data-set, there appeared to be no links between heavy use of cannabis and either childhood sexual abuse or psychosis. The lack of association with psychosis is surprising in view of the wide interest in this link in the clinical and scientific community and 
the findings of other researchers. ${ }^{21,55}$ It has been argued that adolescence may be a critical period, but we had no way of identifying people who were using cannabis heavily in adolescence. Some authors have, however, recently suggested that the link may not be so important at the population level. ${ }^{56}$ Although there may be issues of reportage in our data-set, they would seem unlikely to explain our very clear findings, particularly as there is little stigma attached to cannabis use in the general population of the UK.

\section{The pathways to psychosis}

Although we found evidence that anxiety and depression may mediate the psychosis-abuse relationship, many other candidates have been proposed. Our results certainly leave room for these, and the utility of complex models in driving research is thus maintained. ${ }^{49,50,57}$ Likely candidates are mentally intrusive reminders of the abusive experience; the development of unhelpful psychological processes involving attitudes and beliefs, such as mistrust of others; styles of coping that may impair the processing of the original abuse; and enhanced propensities towards mood dysregulation in the face of subsequent experience. Severe trauma may also persistently modify the physiological stress response in deleterious ways. ${ }^{13,58}$ One putative pathway is that childhood sexual abuse sets up fundamental but dysfunctional schemas about oneself and the world - that the world is a dangerous place, that one is blameworthy or has no one to help. Childhood sexual abuse is often reported by victims as being accompanied by requirements for secrecy, and threats if the secret is broken. Thus no alternative views or explanations can be sought to refute such schemas. Childhood sexual abuse does seem to have disastrous effects on self-esteem and psychological well-being, ${ }^{59-61}$ and results in self-blaming attributions. ${ }^{62}$ It is also linked to paranoia and suspiciousness in non-clinical samples. ${ }^{63}$

Such cognitive and affective attributes are also characteristics of psychosis, ${ }^{64}$ are associated with the development of 'at risk' mental states, ${ }^{65}$ and maintain positive symptoms in those who already have them. ${ }^{50,57,66-68}$ It seems likely that the pre-setting of emotional dysfunction and negative schemas provides an easily triggered automatic negative cognitive pathway. Along this pathway, further life events and stresses will lead to unusual experiences and emotional problems, which can be appraised as external and then understood as symptoms of psychosis. ${ }^{57}$ Likewise avoidant coping is prominent both in survivors of sexual abuse and people with psychosis, and is therefore a candidate for the mediation process. ${ }^{69,70}$ It appears to prevent the resolution of dysfunctional cognitions. Early sexual abuse may block effective social engagement, and lead to an isolation that may itself favour the development of psychotic symptoms. ${ }^{71}$ Thus the mediation of the link between childhood sexual abuse and psychosis is likely to be multifarious and complex. Whereas our demonstration of a mediating role for affect must be treated with reservation, it is consistent with a number of other studies.

\section{Implications for intervention}

Our findings have important implications for social and health policy. People who have experienced sexual abuse are often identified by Social Services and through the criminal justice system. There is also increasing awareness in schools and in primary care. There are thus opportunities for targeted primary and secondary prevention through dealing with the psychological consequences of abuse before psychiatric disorders emerge.

The damage brought about by an experience of sexual abuse will often be hidden by abused persons: although they will usually reveal it to clinicians, it is likely to require questioning that is both direct and sensitive. Such enquiry is an important component of psychiatric treatment and management, ${ }^{72}$ particularly as there is now an argument for introducing specific techniques such as imagery re-scripting ${ }^{73,74}$ into the cognitive-behavioural treatment of psychosis.

Paul Bebbington, PhD, FRCP, FRCPsych, Sarah Jonas, MSC, MRCPsych, Department of Mental Health Sciences, University College London; Elizabeth Kuipers, PhD, Institute of Psychiatry, Kings College London; Michael King, MD, PhD, FRCPsych, Claudia Cooper, PhD, MRCPsych, Department of Mental Health Sciences, University College London; Traolach Brugha, MD, FRCPsych, Health Sciences, University College London; Traolach Brugha, MD, FRCPSych,
Howard Meltzer, PhD, Department of Health Sciences, University of Leicester; Sally McManus, MSC, National Centre for Social Research, London; Rachel Jenkins, $\mathrm{MD}$, FRCPsych, Institute of Psychiatry, Kings College London, UK

Correspondence: Paul Bebbington, Department of Psychiatry \& Behavioural Sciences, Royal Free \& University College Medical School, Holborn Union Building, Archway Campus, Whittington Hospital, Highgate Hill, London N19 5LW, UK. Email: p.bebbington@ucl.ac.uk

First received 10 Jun 2010, final revision 18 Dec 2010, accepted 17 Jan 2011

\section{References}

1 Bebbington $\mathrm{PE}$, Jonas $\mathrm{S}$, Brugha $\mathrm{T}$, Meltzer $\mathrm{H}$, Jenkins $\mathrm{R}$, Cooper $\mathrm{C}$, et al. Child sexual abuse reported by an English national sample: characteristics and demography. Soc Psychiatry Psychiatr Epidemiol 2011; 46: 255-62.

2 May-Chahal C, Cawson P. Measuring child maltreatment in the United Kingdom: a study of the prevalence of child abuse and neglect. Child Abuse Negl 2005; 29: 943-1070.

3 Dinwiddie $S$, Heath AC, Dunne MP, Bucholz KK, Madden PAF, Slutske WS, et al. Early sexual abuse and lifetime psychopathology: a co-twin-control study. Psychol Med 2000; 30: 41-52.

4 Friedman S, Smith L, Fogel D, Paradis C, Viswanathan R, Ackerman R, et al. The incidence and influence of early traumatic life events in patients with panic disorder: a comparison with other psychiatric outpatients. J Anxiety Disord 2002; 16: 259-72.

5 Pereda N, Guilera G, Forns M, Gómez-Benito J. The international epidemiology of child sexual abuse: a continuation of Finkelhor (1994) Child Abuse Negl 2009; 33: 331-42.

6 McManus S, Meltzer H, Brugha T, Bebbington P, Jenkins R. Adult Psychiatric Morbidity in England, 2007: Results of a Household Survey. NHS Information Centre, 2009 (http://www.ic.nhs.uk/pubs/psychiatricmorbidity07).

7 Kendler KS, Bulik CM, Silberg J, Hettema JM, Myers J, Prescott CA. Childhood sexual abuse and adult psychiatric and substance use disorders in women an epidemiological and cotwin control analysis. Arch Gen Psychiatry 2000; 57: 953-9.

8 Bebbington PE, Bhugra D, Brugha T, Singleton N, Farrell M, Jenkins R, et al. Psychosis, victimisation and childhood disadvantage. Evidence from the second British National Survey of Psychiatric Morbidity. Br J Psychiatry 2004; 185: 220-6.

9 Bebbington PE, Cooper C, Minot S, Brugha TS, Jenkins R, Meltzer H, et al. Suicide attempts, gender and sexual abuse: data from the British psychiatric morbidity survey 2000. Am J Psychiatry 2009; 166: 1135-40.

10 Chen LP, Murad MH, Paras ML, Colbenson KM, Sattler AL, Goranson EN, et al. Sex abuse and lifetime diagnosis of psychiatric disorders: systematic review and meta-analysis. Mayo Clinic Proceedings 2010; 85: 618-29.

11 Jonas S, Bebbington PE, McManus S, Meltzer H, Jenkins R, Kuipers E, et al. Sexual abuse and psychiatric disorder in England: results from the 2007 Adult Psychiatric Morbidity Survey. Psychol Med 2011; 41: 709-20.

12 Janssen I, Krabbendam L, Bak M, Hanssen M, Vollebergh W, de Graaf R, et al. Childhood abuse as a risk factor for psychotic experiences. Acta Psychiatr Scand 2004; 109: 38-45.

13 Read J, van Os J, Morrison AP, Ross CA. Childhood trauma, psychosis and schizophrenia: a literature review with theoretical and clinical implications. Acta Psychiatr Scand 2005; 112: 330-50.

14 Bebbington PE. Childhood sexual abuse and psychosis: aetiology and mechanism. Epidemiol Psichiatr Soc 2009; 18: 284-93.

15 Hardy A, Fowler D, Freeman D, Smith B. Steel C, Evans J, et al. Trauma and hallucinatory experience in psychosis. J Nerv Menl Dis 2005; 193: 501-7.

16 Gracie A, Freeman D, Green S, Garety PA, Kuipers E, Hardy A, et al. The association between traumatic experience, paranoia and hallucinations: a test of psychological models. Acta Psychiatr Scand 2007; 116: 280-9. 
17 Jenkins R, Meltzer H, Bebbington $\mathrm{P}$, Brugha T, Farrell M, McManus S, et al. The British Mental Health Survey Programme: achievements and latest findings. Soc Psychiatry Psychiatr Epidemiol 2009; 44: 899-904.

18 Kish L. Survey Sampling. John Wiley and Sons, 1965.

19 World Health Organization. SCAN: Schedules for Clinical Assessment in Neuropsychiatry. WHO, 1992.

20 Lewis G, Pelosi AJ, Araya R, Dunn G. Measuring psychiatric disorder in the community: a standardized assessment for use by lay interviewers. Psychol Med 1992; 22: 465-86

21 Moore TMH, Zammit S, Lingford-Hughes A, Barnes TRE, Jones PB, Burke $\mathrm{M}$, et al. Cannabis use and risk of psychotic or affective mental health outcomes: a systematic review. Lancet 2007; 370: 319-28.

22 Bebbington PE, Nayani T. The Psychosis Screening Questionnaire. Int J Methods Psychiatr Res 1995; 5: 11-20.

23 World Health Organization. The ICD-10 Classification of Mental and Behavioural Disorders: Clinical Descriptions and Diagnostic Guidelines. WHO, 1992.

24 Sadler K, Bebbington P. Psychosis. In Adult Psychiatric Morbidity in England 2007: Results of a Household Survey (eds S McManus, H Meltzer, TS Brugha, PE Bebbington, R Jenkins). The NHS Information Centre for Health and Socia Care, 2009.

25 Baron RM, Kenny DA. The moderator mediator variable distinction in social psychological research - conceptual, strategic, and statistical considerations. J Pers Soc Psychol 1986; 51: 1173-82.

26 Olff M, Langeland W, Draijer N, Gersons BP. Gender differences in posttraumatic stress disorder. Psychol Bull 2007; 133: 183-204.

27 Tourangeau R, Rips LJ, Rasinski K. The Psychology of Survey Response. Cambridge University Press, 2000.

28 Fergusson DM, Horwood LJ, Woodward LJ. The stability of child abuse reports: a longitudinal study of the reporting behaviour of young adults. Psychol Med 2000; 30: 529-44.

29 Goodman LA, Thompson KM, Weinfurt K, Corl S, Acker P, Mueser KT, et al. Reliability of reports of violent victimization and posttraumatic stress disorder among men and women with serious mental health. J Trauma Stress 1999; 12: 587-99.

30 Fisher HL, Craig TK, Fearon P, Morgan K, Dazzan P, Lappin J, et al. Reliability and comparability of psychosis patients' retrospective reports of childhood abuse. Schizophr Bull 2009; Oct 7 (Epub ahead of print).

31 Myin-Germeys I, Krabbendam L. Sex differences in emotional reactivity to daily life stress in psychosis. J Clin Psychiatry 2004; 65: 805-9.

32 Singleton N, Bumpstead R, O'Brien M, Lee A, Meltzer H. Psychiatric Morbidity Among Adults Living in Private Households, 2000. TSO (The Stationery Office), 2001.

33 Whitfield CL, Dube SR, Felitti VJ, Anda RF. Adverse childhood experiences and hallucinations. Child Abuse Neg/ 2005; 29: 797-810.

34 Lataster T, van Os J, Drukker M, Henquet C, Feron F, Gunther N, et al. Childhood victimisation and developmental expression of non-clinical delusional ideation and hallucinatory experiences: victimisation and non-clinical psychotic experiences. Soc Psychiatry Psychiatr Epidemiol 2006; 41: 423-8.

35 Spauwen J, Krabbendam L, Lieb R, Wittchen H-U, van Os J. Impact of psychological trauma on the development of psychotic symptoms: relationship with psychosis proneness. Br J Psychiatry 2006; 188: 527-33.

36 Deloore E, Drukker M, Gunther N, Feron F, Deboutte D, Sabbe B, et al. Childhood negative experiences and subclinical psychosis in adolescence: a longitudinal general population study. Early Interv Psychiatry 2007; 1: 201-7.

37 Scott J, Chant D, Andrews G, Martin G, McGrath J. Association between trauma exposure and delusional experiences in a large community-based sample. Br J Psychiatry 2007; 190: 339-43.

38 Shevlin M, Dorahy MJ, Adamson G. Trauma and psychosis: an analysis of the National Comorbidity Survey. Am J Psychiatry 2007; 164: 166-9.

39 Kelleher I, Harley M, Lynch F, Arseneault L, Fitzpatrick C, Cannon M. Associations between childhood trauma, bullying and psychotic symptoms among a school-based adolescent sample. Br J Psychiatry 2008; 193: 378-82.

40 Shevlin M, Houston JE, Dorahy MJ, Adamson G. Cumulative traumas and psychosis: an analysis of the national comorbidity survey and the British Psychiatric Morbidity Survey. Schizophr Bull 2008; 34: 193-9.

41 Fisher H, Morgan C, Dazzan P, Craig TK, Morgan K, Hutchinson G, et al. Gender differences in the association between childhood abuse and psychosis. Br J Psychiatry 2009; 194: 319-25.

42 Freeman D, Fowler D. Routes to psychotic symptoms: trauma, anxiety and psychosis-like experiences. Psychiatry Res 2009; 169: 107-12.
43 Schreier A, Wolke D, Thomas K, Horwood J, Hollis C, Gunnell D, et al. Prospective study of peer victimization in childhood and psychotic symptoms in a nonclinical population at age 12 years. Arch Gen Psychiatry 2009; 66: 527-36

44 Arseneault L, Cannon M, Fisher HL, Polanczyk G, Moffitt TE, Caspi A Childhood trauma and children's emerging psychotic symptoms: a genetically sensitive longitudinal cohort study. Am J Psychiatry 2011; 168: 65-72.

45 Elklit A, Shevlin M. Female sexual victimization predicts psychosis: a casecontrol study based on the Danish Registry System. Schizophr Bull 2010; May 20 (Epub ahead of print).

46 Mackie CJ, Castellanos-Ryan N, Conrod PJ. Developmental trajectories of psychotic-like experiences across adolescence: impact of victimization and substance use. Psychol Med 2011; 41: 47-58.

47 Shevlin M, Dorahy MJ, Adamson G. Trauma and psychosis: an analysis of the National Comorbidity Survey. Am J Psychiatry 2007; 164: 166-9.

48 Lysaker PH, Davis LW, Gatton MJ, Herman SM. Associations of anxietyrelated symptoms with reported history of childhood sexual abuse in schizophrenia spectrum disorders. J Clin Psychiatry 2005; 66: 1279-84.

49 Garety PA, Freeman D, Jolley S, Dunn G, Bebbington PE, Fowler D, et al. Reasoning, emotions and delusional conviction in psychosis. $J$ Abnorm Psychol 2005; 114: 373-84

50 Garety PA, Bebbington P, Fowler D, Freeman D, Kuipers E. Implications for neurobiological research of cognitive models of psychosis: a theoretical paper. Psychol Med 2007; 37: 1377-91.

51 Read J, Agar K, Argyle N, Aderhold V. Sexual and physical abuse during childhood and adulthood as predictors of hallucinations, delusions and thought disorder. Psychol Psychother 2003; 76: 11-22.

52 Classen CC, Palesh OG, Aggarwal R. Sexual revictimization: a review of the empirical literature. Trauma Violence Abuse 2005; 6: 103-29.

53 Cloitre $M$, Rosenberg, A. Sexual revictimization: risk factors and prevention. In Cognitive-Behavioral Therapies for Trauma (eds VM Follette, JI Ruzek): 321-61. Guilford, 2006.

54 Goodman LA, Salyers MP, Mueser KT, Rosenberg SD, Swartz M, Essock SM, et al. Recent victimization in women and men with severe mental illness: prevalence and correlates. J Trauma Stress 2001; 14: 615-32.

55 Harley M, Kelleher I, Clarke M, Lynch F, Arseneault L, Connor D, et al. Cannabis use and childhood trauma interact additively to increase the risk of psychotic symptoms in adolescence. Psychol Med 2010; 40: 1627-34.

56 Hickman M, Vickerman P, Macleod J, Lewis G, Zammit S, Kirkbride J, et al. If cannabis caused schizophrenia - how many cannabis users may need to be prevented in order to prevent one case of schizophrenia? England and Wales calculations. Addiction 2009; 104: 1856-61.

57 Garety P, Kuipers E, Fowler D, Freeman D, Bebbington P. Theoretical paper: a cognitive model of the positive symptoms of psychosis. Psychol Med 2001; 31: 189-95.

58 Heim C, Newport DJ, Miller AH. Nemeroff CB. Long term neuroendocrine effects of childhood maltreatment. J Am Med Assoc 2000; 284: 2321.

59 Kamsner S, McCabe MP. The relationship between adult psychological adjustment and childhood sexual abuse, childhood physical abuse, and family-of-origin characteristics. J Interpers Violence 2000; 15: 1243-61.

60 Banyard VL, Williams LM, Siegel JA. The long-term mental health consequences of child sexual abuse: an exploratory study of the impact of multiple traumas in a sample of women. J Trauma Stress 2001; 14: 697-715.

61 Murthi M, Espelage DL. Childhood sexual abuse, social support, and psychological outcomes: a loss framework. Child Abuse Negl 2005; 29 1215-31.

62 Mannarino AP, Cohen JA. Abuse-related attributions and perceptions, general attributions, and locus of control in sexually abused girls. J Interpers Violence 1996; 11: 162-80.

63 Steel C, Marzillier S, Fearon P, Ruddle A. Childhood abuse and schizotypal personality. Soc Psychiatry Psychiatr Epidemiol 2009; 44: 917-23.

64 Fowler D, Freeman D, Smith B, Kuipers E, Bebbington $P$, Bashforth $H$, et al. The Brief Core Schema Scales (BCSS): psychometric properties and associations with paranoia and grandiosity in non-clinical and psychosis samples. Psychol Med 2006; 36: 749-59.

65 Birchwood M. Pathways to emotional dysfunction in first-episode psychosis. Br J Psychiatry 2003; 182: 373-5.

66 Kuipers E, Garety P, Fowler D, Freeman D, Dunn G, Bebbington P. Cognitive, emotional and social processes in psychosis: refining cognitive behavioural therapy for persistent positive symptoms. Schizophr Bull 2006; 32: S24-31.

67 Krabbendam L, Myin-Germeys I, Hanssen M, de Graaf R, Vollebergh W, Bak M, et al. Development of depressed mood predicts onset of psychotic disorder in individuals who report hallucinatory experiences. Br J Clin Psychol 2005; 44: $113-25$ 
68 Smith B, Fowler DG, Freeman D, Bebbington P, Bashforth H, Garety P, et al Emotion and psychosis: links between depression, self-esteem, negative schematic beliefs and delusions and hallucinations. Schizophr Res 2006; 86 : 181-8.

69 O'Leary PJ. Men who were sexually abused in childhood: coping strategies and comparisons in psychological functioning. Child Abuse Negl 2009; 33: 471-9.

70 Cooke M, Peters E, Fannon D, Anilkumar APP, Aasen I, Kuipers E, et al. Insight, distress and coping styles in schizophrenia Schizoph Res 2007; 94: 12-22.
71 White R, Bebbington P, Pearson J, Johnson S, Ellis D. The social context of insight in schizophrenia. Soc Psychiatry Psychiatr Epidemiol 2000; 35: 500-7.

72 Holmes EA, Arntz A, Smucker MR. Imagery rescripting in cognitive behaviour therapy: images, treatment techniques and outcomes. J Behav Ther Exper Psychiatry 2007; 38: 297-305.

73 Read J, Hammersley P, Rudegeair T. Why, when and how to ask about childhood abuse. Adv Psychiatr Treat 2007; 13: 101-10.

74 Linden $\mathrm{M}$, Zehner $\mathrm{A}$. The role of childhood sexual abuse (CSA) in adult cognitive behaviour therapy. Behav Cogn Psychother 2007; 35: 447-55.

\section{extra Letter to Father}

\section{Franz Kafka}

At that time, and whenever possible at that time, I could have used some encouragement. I was, after all, already weighed down by your sheer physical presence. I remember, for example, how we often undressed together in the same changing-room. I was skinny, weakly, slight; you were strong, tall, broad. Even in the changing-room I felt pitiful, and what's more, not only in your eyes, but in the eyes of the entire world, for you were for me the standard by which everything was measured. When we stepped out of the changing-room in front of everyone - I holding your hand, a small skeleton, insecure, barefoot on the planks, afraid of the water, incapable of copying your swimming strokes, which you, with good intentions but actually to my profound shame, kept on demonstrating to me - then at such moments I was full of despair and all my bad experiences in all areas tallied marvelously. I felt happiest when you sometimes undressed first and I could stay in the changing-room alone and postpone the shame of appearing in public until you at last came looking for me and drove me out of the changing-room. I was grateful to you that you did not appear to notice my anguish; I was proud, too, of my father's body. Incidentally, this difference between us still exists much the same today.

Franz Kafka (1883-1924) is best known for his novels The Trial, The Castle, and the novella Metamorphosis. His Letter to Father was written in 1919 but never sent and it was published posthumously. This excerpt is from Letter to Father (pp. 15-16), translated by K. Reppin, published by Vitalis 1999.

Chosen by Femi Oyebode 